\title{
A distinct response to endogenous DNA damage in the development of Nbs1-deficient cortical neurons
}

\author{
Rui $\mathrm{Li}^{1}$, Yun-Gui Yang ${ }^{2}$, Yunzhou Gao ${ }^{1}$, Zhao-Qi Wang ${ }^{3,4}$, Wei-Min Tong ${ }^{1}$ \\ ${ }^{I}$ Department of Pathology and Center for Experimental Animal Research, Institute of Basic Medical Sciences, Chinese Academy \\ of Medical Sciences \& Peking Union Medical College (PUMC), 5 Dong Dan San Tiao, Beijing 100005, China, ${ }^{2}$ Genome Structure \\ \& Stability Group, Disease Genomics and Individualized Medicine Laboratory, Beijing Institute of Genomics, Chinese Academy \\ of Sciences, Beijing 100029, China; ${ }^{3}$ Leibniz Institute for Age Research - Fritz Lipmann Institute; ${ }^{4}$ Faculty of Biology-Pharmacy, \\ Friedrich-Schiller-University Jena, 07745 Jena, Germany
}

Microcephaly is a clinical characteristic for human nijmegen breakage syndrome (NBS, mutated in NBS1 gene), a chromosomal instability syndrome. However, the underlying molecular pathogenesis remains elusive. In the present study, we demonstrate that neuronal disruption of $N B S$ ( $N b n$ in mice) causes microcephaly characterized by the reduction of cerebral cortex and corpus callosum, recapitulating neuronal anomalies in human NBS. Nbs1-deficient neocortex shows accumulative endogenous DNA damage and defective activation of Ataxia telangiectasia and Rad3related (ATR)-Chk1 pathway upon DNA damage. Notably, in contrast to massive apoptotic cell death in Nbs1deficient cerebella, activation of $\mathbf{p 5 3}$ leads to a defective neuroprogenitor proliferation in neocortex, likely via specific persistent induction of hematopoietic zinc finger (Hzf) that preferentially promotes p53-mediated cell cycle arrest whilst inhibiting apoptosis. Moreover, Trp53 mutations substantially rescue the microcephaly in Nbs1-deficient mice. Thus, the present results reveal the first clue that developing neurons at different regions of brain selectively respond to endogenous DNA damage, and underscore an important role for Nbs1 in neurogenesis.

Keywords: DNA damage response; Nbs1; microcephaly; p53; Hzf

Cell Research (2012) 22:859-872. doi:10.1038/cr.2012.3; published online 3 January 2012

\section{Introduction}

Nijmegen breakage syndrome (NBS), caused by hypomorphic mutation in NBS1 [1], is a chromosomal instability syndrome, characterized by chromosomal instability, immunodeficiency, radiosensitivity, cancer predisposition and microcephaly. The Nbs1/Nibrin/p95 protein is a component of the Mre11/Rad50/Nbs1 (MRN) complex that acts as a DNA double-strand break (DSB) sensor and functions in cell cycle checkpoint in response to DNA damage and DNA repair together with Ataxia telangiectasia mutated (ATM), Ataxia telangiectasia and Rad3-related (ATR), mediator of DNA damage checkpoint protein 1 (MDC1) and H2AX [2]. Following DSBs

Correspondence: Wei-Min Tong

Tel: +86-10-6529-5942; Fax: +86-10-6523-2759

E-mail: wmtong@ibms.pumc.edu.cn

Received 3 August 2011; revised 2 November 2011; accepted 30 November 2011; published online 3 January 2012 in DNA, Nbs1 interacts with phosphorylated H2AX $(\gamma \mathrm{H} 2 \mathrm{AX})$ and is responsible for the nuclear translocation of the Mre11/Rad50 repair complex to the sites of DNA damage to sense DNA strand breaks and activate ATM [3-5]. In addition, Nbs1 is phosphorylated by ATM, activating downstream molecules including p53, BRCA1 and Chk2 to control cell cycle progression $[6,7]$. Moreover, it has also been demonstrated that the MRN complex plays a role in single-strand break (SSB) -mediated ATR activation and subsequent phosphorylation of Chk1 $[8,9]$. Thus, Nbs1 or MRN also participates in mediating activation of ATM and ATR directly or indirectly [2, 10, $11]$.

Genetic defects in DNA damage response (DDR) lead to human microcephaly syndromes, such as Nijmegen breakage syndrome, ATR Seckel syndrome (mutated in $A T R$ [12]), and primary microcephaly (MCPH) caused by mutations in MCPH1 [13]. These syndromes share overlapping neuronal defects, indicating that microcephaly may be caused by alterations of neuronal progenitors in 
response to DNA damage.

To study the molecular pathogenesis of microcephaly induced by DDR defects in humans, attempts have been made using mouse models with disruption of NBS1 (known as Nbn in mice) and ATR. Due to their essential nature in cellular function, null mutation of $\mathrm{Nbn}$ and $A T R$ in mice lead to embryonic lethality $[14,15]$. Although mice with hypomorphic mutations of $\mathrm{Nbn}$ are viable, they do not show obvious brain phenotypes seen in human NBS [16]. When we specifically deleted $N b n$ in mouse central nervous system (CNS) using Cre-loxP, these mice $\left(\mathrm{Nbn}^{\mathrm{CNS}-\mathrm{del}}\right.$ mice) exhibited growth retardation and early onset of cataracts [17]. The most striking phenotype of these mice is an early postnatal ataxia caused by the agenesis of the cerebellum with decreased proliferation in neuronal progenitors, and massive cell death in cerebellar neuronal cells [18]. In addition, $\mathrm{Nbn}^{\mathrm{CNS}-\mathrm{del}}$ mice displayed microcephaly and severely affected white matter integrity, retina and astrocyte functionality [1921]. However, the nature of cerebral reduction and the underlying molecular mechanism in $\mathrm{Nbn}^{\mathrm{CNS}-\mathrm{del}}$ mice have not been investigated.

\section{Results}

\section{Neuronal disruption of Nbs1 leads to microcephaly}

Macroscopically, the size and shape of the cerebrum was greatly reduced in the $N b n^{C N S-d e l}$ mice compared to its counterpart starting from postnatal day 7 (P7), becoming more evident at P14 and P21. The maximum width of hemisphere in 2-month-old $\mathrm{Nbn}^{\mathrm{CNS}-\mathrm{del}}$ and $\mathrm{Nbn}^{\mathrm{CNS}-\mathrm{ctr}}$ mice is around $4.3 \pm 2 \mathrm{~mm}$ and $5.2 \pm 2.3 \mathrm{~mm}$, respectively (averaged from more than 20 mice of each group, $P<0.01$ $(t$-test), Figure 1A). To study the effect of neuronal deletion of $N b n$ in cerebrum, we performed histological analysis on the $N b n^{C N S-d e l}$ brain between P7 and P21 and revealed a general $(\sim 20 \%)$ reduction in thickness of the cerebral cortex compared to their littermate controls (Figure 1B). To examine the distinct morphological identities of cerebral cortex in details, we performed immunostaining with a neuronal-specific marker, neuronal nuclei (NeuN; Figure 1C). The cortex of the control mice is characterized by six laminas, which could be distinguished by packing density and neural morphology (Figure 1C). This laminar cortical structure was altered in $\mathrm{Nbn}^{\mathrm{CNS}-}$ ${ }^{d e l}$ mice (Figure 1C). Although the layer I that contains Cajal-Retzius cells was similar to that in the $\mathrm{Nbn}^{\mathrm{CNS}-\mathrm{ctr}}$ cortex, the thickness of layer II/III that contains small pyramidal cells was reduced with less neuron cellularity ( $\sim 76 \%$ of that in the $N b n^{C N S-c t r}$ cortex, Figure $1 \mathrm{C}$ and $\left.1 \mathrm{D}\right)$. In addition, layers IV and V, where granule cells (GC) and large pyramidal cells localize, respectively, were less recognizable and their thickness and the cellularity was also decreased ( $78 \%$ of that in the $N b n^{C N S-c t r}$ cortex, Figure 1C and 1D). However, the layer VI contained the similar number of polymorphic cells compared to that in $\mathrm{Nbn}^{\mathrm{CNS}-\mathrm{ctr}}$ cerebral cortex (Figure 1C and 1D).

Similar to NBS patients, the thickness of the corpus callosum (CC) was reduced in $\mathrm{Nbn}^{\mathrm{CNS}-\mathrm{del}}$ brain (Figure $1 \mathrm{~B}, 1 \mathrm{E}$ and $1 \mathrm{~F})$. As $\mathrm{CC}$ is composed by tightly packed neural axon wrapped with myelin sheath of glial cells, we further examined myelin basic protein (MBP) and found that the density and thickness of MBP-stained neural fibers were markedly decreased (Figure 1E). There was a dramatic reduction of the number of medial habenular neurons (Mhb) (Figure 1B), and mild alterations of the fasciole cinereum (fc) in $N b n^{C N S-d e l}$ mice (Figure 1B). The size of thalamic and hypothalamic region in $\mathrm{Nbn}^{\mathrm{CNS}-}$ ${ }^{d e l}$ mice was also proportionally reduced compared to that in control brains (Figure 1B). Neurons in the CA1, CA3 field and dentate gyrus (DG) of $\mathrm{Nbn}^{\mathrm{CNS}-d e l}$ hippocampus were less densely packed from P7 to P21 (Figure 1E). In addition, $N b n^{C N S-d e l}$ mice displayed an increased number of neurons in the polymorph layer DG (PoDG, Figure 1E). The microcephaly has been observed in $N b n^{\text {CNS-del }}$ mice of 129/SV $\times$ C57/BL6 mixed background originated from two independent ES clones.

\section{Nbs 1 deficiency causes severe disruption of olfactory} bulb morphogenesis

Strikingly, $\mathrm{Nbn}^{\mathrm{CNS}-\mathrm{del}}$ mice displayed a severely altered olfactory bulb (OB). At low magnification, NeuN immunostaining showed that the morphology of the $N b n^{\text {CNS-del }}$ OB differed from that of the $N b n^{\text {CNS-ctr }}$ mice (Supplementary information, Figure S1A). For instance, in the $N b n^{C N S-c t r} \mathrm{OB}$, each cell population was laminated at the defined structure, whereas $\mathrm{Nbn}^{\mathrm{CNS}-\mathrm{del}} \mathrm{OB}$ displayed a reduced cellularity and less defined laminar structure (Supplementary information, Figure S1A, left panel). Further examination of the OB structure under high magnification revealed three major differences between $N b n^{C N S-c t r}$ and $N b n^{C N S-d e l}$ mice. First, although olfactory nerve layer (ONL) and glomerular layer (GL), where the dendrites of second-order neurons form spheroidal structure, glomeruli, were present in $\mathrm{Nbn}^{\mathrm{CNS}-\mathrm{del}}$ mice, the number of the periglomerular neurons was reduced (arrows, Supplementary information, Figure S1A). Second, the superficial external plexiform layer (EPL) and the laminar structure of the mitral cell layer (ML) were less defined in the $\mathrm{Nbn}^{C N S-d e l}$ mice (Supplementary information, Figure S1A). Third, a significant decrease in the number of GCs was observed in all $N b n^{C N S-d e l}$ OBs analyzed from P1 to P21 (Supplementary information, Figure S1A and data not shown). 
A

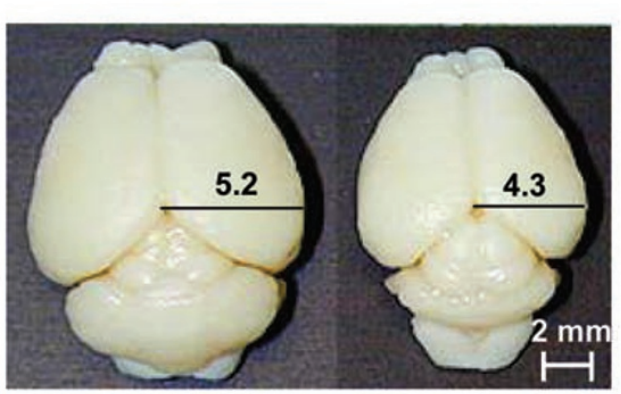

C

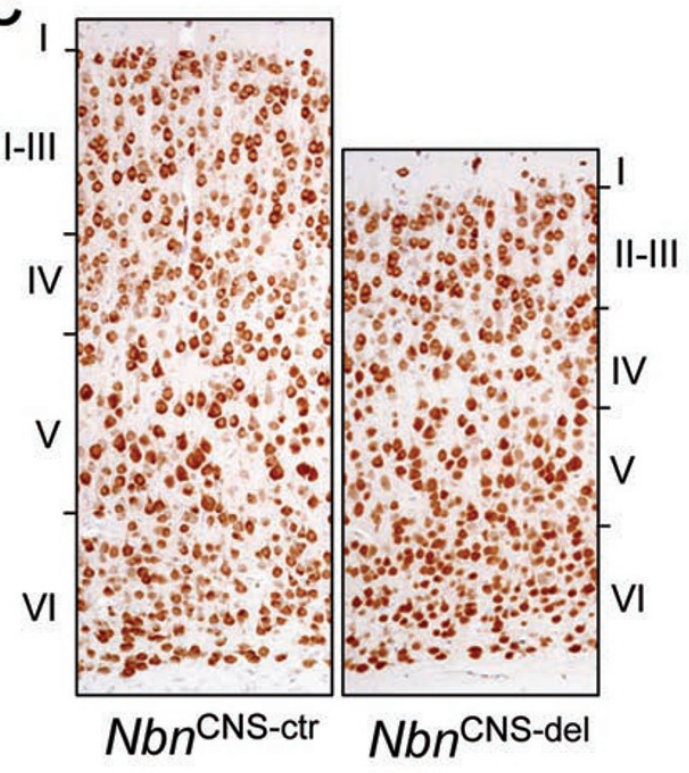

E

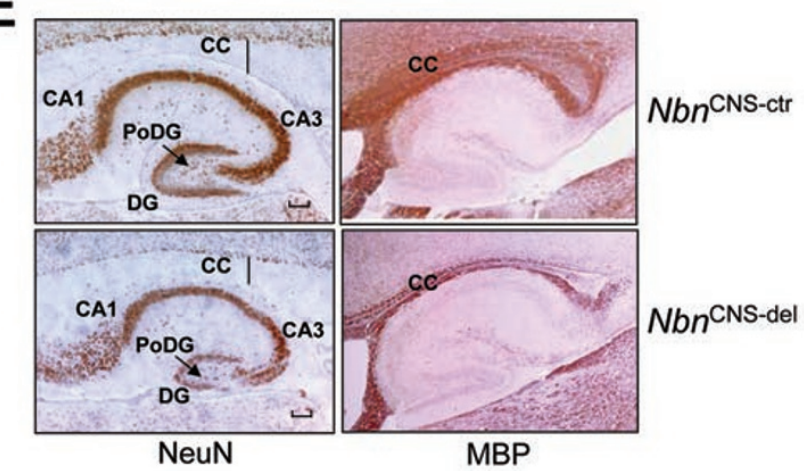

B
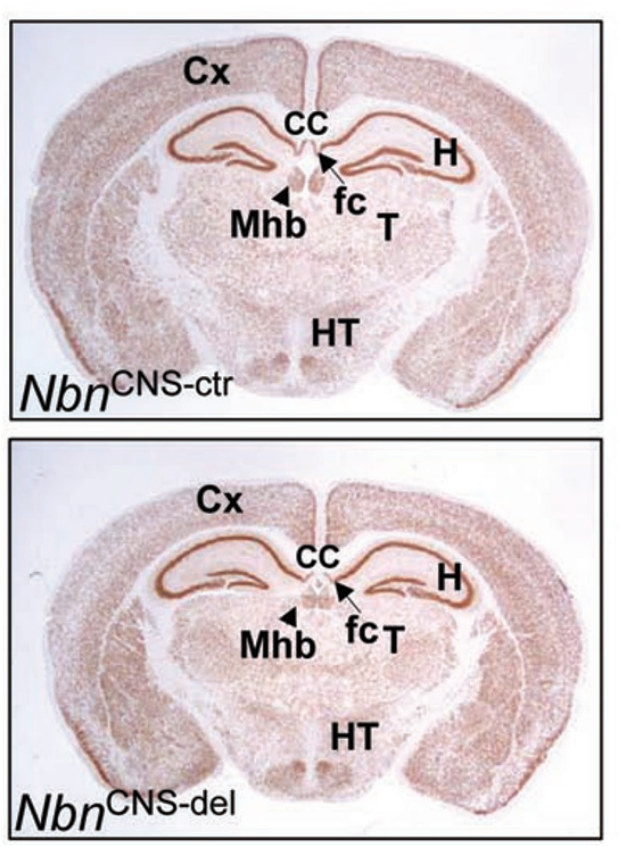

D

$0 \mathrm{Nbn}$ CNS-ctr प Nbn ${ }^{\mathrm{CNS}-\mathrm{del}}$

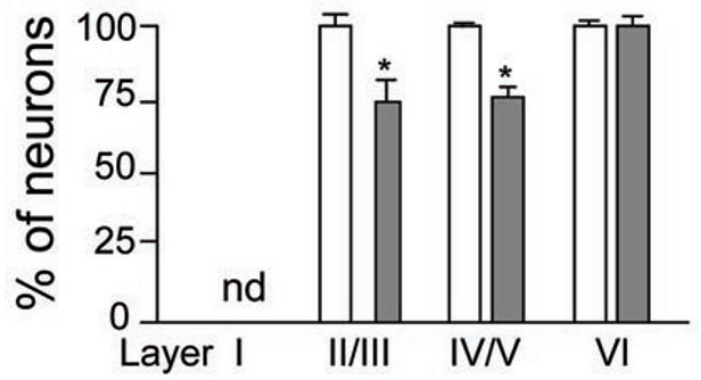

F

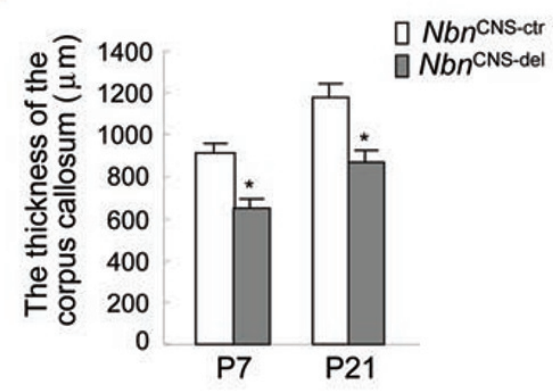

Figure $1 \mathrm{Nbs} 1$ deficiency leads to microcephaly. (A) Macroscopic view of reduced cerebral size in $N b n^{\mathrm{CNS}-d e l}$ brain, $n=20$, $P<0.01$ ( $t$ test). (B) NeuN staining of coronal section of the cerebrum at postnatal day 21 (P21), original magnification $\times 1$. Cx, cerebral cortex; CC, corpus callosum; H, hippocampus; fc, fasciole cinerum; Mhb, medial habenular neurons; T, thalamic region; HT, hypothalamic region. (C) Representative laminar cortical structure in control and $\mathrm{Nbn}^{\text {CNS-del }}$ mice. (D) Histogram showing the percentage of neurons in each layer of $\mathrm{Nbn}{ }^{\mathrm{CNS}-d e l}$ cerebral cortical sections compared to control mice. At least 10 mice of each genotype were analyzed, ${ }^{*} P<0.01$ ( $t$ test). (E) Representative P7 hippocampus with NeuN staining (left). DG, dentate gyrus; CA1/CA3, field CA1/CA3 of hippocampus; PoDG, polymorph layer dentate gyrus. Bar is $1 \mathrm{~mm}$. Representative

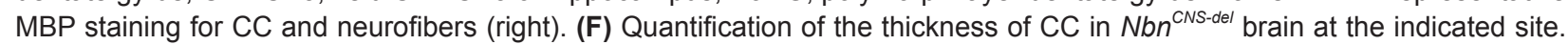
Original magnification $\times 10$. At least 10 mice of each genotype were analyzed, ${ }^{*} P<0.01$ ( $t$ test). 
The OB is formed postnatally [22]. Immature neurons generated from neural stem cells in the subventricular zone (SVZ) migrate towards each other in chains through the rostral migratory stream (RMS) to the OB (Supplementary information, Figure S1B). To investigate the defect of olfactory neurogenesis in $N b n^{C N S-d e l}$ mice, we pulse labeled mice with bromodeoxyuridine (BrdU). From $\mathrm{P} 0$ to $\mathrm{P} 7$, proliferating neuroprogenitors in the SVZ of the lateral ventricles (LV) were greatly reduced in the $N b n^{C N S-d e l}$ mice compared to that in the controls (Supplementary information, Figure S1B). In addition, BrdUpositive neurons in the RMS were also reduced in the $\mathrm{Nbn}{ }^{\mathrm{CNS}-\mathrm{del}}$ mice compared to that in the controls (Supplementary information, Figure S1B).

Nbs1 deficiency impairs ATR-Chk1 signaling in response to endogenous DNA damage in developing brain

Nbs1 is a key DDR molecule and DDR is critical for the development of the CNS [23]. We next evaluated the level of endogenous DNA damage in $\mathrm{Nbn}^{\mathrm{CNS}-\mathrm{del}}$ neocortex by immunohistochemical analysis on a DNA strand break marker, phosphorylated $\mathrm{H} 2 \mathrm{AX}(\gamma \mathrm{H} 2 \mathrm{AX})$. In contrast to $N b n^{C N S-c t r}$ neocortex, increased $\gamma \mathrm{H} 2 \mathrm{AX}$ not only occurred in proliferating neural precursor cells at ventricular zone (VZ), but also aggregated in postmitotic neurons at the mantle zone (MZ) of Nbn-deficient brain (Figure 2A). This suggests that Nbs1 deficiency leads to accumulation of endogenous DNA damage in line with spatial and temporal proliferation pattern during the cerebral development. Therefore, we speculated that stalled replication forks during cell proliferation and oxidative damage from cellular metabolism contribute to physiological endogenous DNA damage, which could activate ATM/ ATR signaling through Nbs1 or MRN complex and subsequently induce activation of downstream substrate p53 to control cell proliferation and/or apoptosis (Figure 2B).

We further explored the role of Nbs1 deficiency in ATM and ATR signaling during cerebral genesis in vivo. As proliferation of cerebral neuroprogenitors in ventricular zone start at E11-E12, we analyzed damage response signaling in embryonic cerebra from E12.5 to E18.5 by western blotting. We found an efficient deletion of Nbs1 after E12.5, and nearly complete absence of Nbs1 protein at E15.5 and E18.5 (Figure 2C). Notably, ATRmediated phosphorylation of Chk1 at serine-345 (Chk1$\mathrm{S} 345 \mathrm{p})$ in $N b n^{\text {CNS-del }}$ embryonic cortex (E15.5-E18.5) was largely compromised (Figure 2C). However, compatible with the $N b n^{C N S-c t r}$ brain, endogenous DNA damage in the $N b n^{\text {CNS-del }}$ brain activated ATM indicated by phosphorylation of ATM at serine-1987 (ATM-S1987p, equivalent to Ser1981 of human ATM), and also phosphorylated its downstream target Chk2 (Supplementary information,
Figure S2).

\section{Nbs 1 deficiency impairs Chk1 localization to sites of} DNA damage in developing neuron

To further investigate Nbs1-mediated activation of ATR signaling at a single cell level, we analyzed the phosphorylation of Chk1 (Chk1-S345p) in primary cultured neural progenitors verified by nestin immunoactivity (Figure 3A). In response to hydroxylurea (HU)-induced replication fork blockage, Chk1-S345p was recruited to the sites of replication fork and formed foci in Nbs1proficient neurons (Figure 3A). Consistent with western blot analysis (Figure 2C), Nbs1-deficient neurons were devoid of Chk1-S345p foci in response to HU-induced replication fork blockage (Figure 3A). As Nbs1 and ATR have been shown in regulating BRCA1 protein focus formation responding to DNA damage [24, 25], immunofluorescence staining of BRCA1 revealed that replication fork blockage caused by HU failed to induce BRCA1 foci in Nbs1-deficient neurons (Figure 3B). However, Nbs1 deficiency did not affect the phosphorylated histone $\mathrm{H} 2 \mathrm{AX}(\gamma \mathrm{H} 2 \mathrm{AX})$ focus formation in HU-treated developing neuron (Figure 3C). The nature of Nbs1-deficient primary neuron was verified by the lack of Mre11 and Rad50 foci, and Mre11 retained in the cytoplasm in the absence of Nbs1 in response to replication blockage (Figure 3D and data not shown). These results indicate that in neocortex, Nbs1 deficiency mainly affects ATRmediated DNA damage response.

\section{Nbs1 deficiency results in proliferation defects of neu-} ronal progenitor cells

Since ATM-Chk2 signaling remains functional in Nbs1-deficient neocortex (Supplementary information, Figure S2), we next explored the consequence of phosphorylation of ATM and Chk2 occurring in Nbs1deficient developing cortex. Immunostaining and western blot analysis of ATM downstream target p53 revealed an accumulation of the $\mathrm{p} 53$ protein in the $\mathrm{VZ}$ and $\mathrm{MZ}$ in Nbs1-deficient developing cortex (Figure 4A and 4B). In addition, immunoactivity of $\mathrm{p} 21$ and its mRNA level were detected in the $\mathrm{VZ}$ and $\mathrm{MZ}$ of Nbs1 mutant mice (Figure 4A and 4C), suggesting a defective proliferation of cortical neuroprogenitors. To further confirm the impact of increased p53 and p21 on cell proliferation, we performed histological assay by in vivo labeling with BrdU. During neurogenesis, proliferating neuroprogenitors (BrdU-positive cells) at VZ exit from cell cycle and migrate to the MZ, becoming postmitotic neurons (Figure 4D). Consistent with the role of Nbs1 in cerebellar neuroprogenitors [18] and in the lens epithelium [17], Nbs1 deficiency led to a significant reduction of BrdU- 
positive neuroprogenitors at E12.5 and E15.5 compared to their $\mathrm{Nbn}^{\mathrm{CNS}-\mathrm{ctr}}$ counterparts (Figure 4D and 4E, data not shown).

Nbs 1 deficiency does not affect neocortical neuronal apoptosis

Since p53 activation by Nbs1 deficiency leads to massive apoptosis in cerebella [18], we next evaluated the cell death in $\mathrm{Nbn}^{\mathrm{CNS}-\mathrm{del}}$ neocortex. Histological analysis of $\mathrm{Nbn}^{\mathrm{CNS}-\mathrm{del}}$ and control neocortex revealed no apparent pyknotic cells from E15.5 (Figure 5A) to E18.5 (data not shown), and negative for active caspase 3 immunoactivity. On the contrary, pyknotic cells with fragmented nuclei that are positive for active caspase 3 immunoactivity were frequently observed in $\mathrm{Nbn}{ }^{\mathrm{CNS}-\mathrm{del}}$ medullar oblonga- ta compared to that in $\mathrm{Nbn}{ }^{\text {CNS-Ctr }}$ mice (Figure 5A, active caspase 3 positive cells/field at $40 \times$ original magnification: $12.4 \pm 2.3$ versus $1.4 \pm 1.1, n=8, P<0.001$ ).

In $N b n^{C N S-d e l}$ brain, although p53 was activated ubiquitously (Figure 4A), the impact of Nbs1 deficiency on neuronal apoptosis in different regions of the brain seems different. DDR-mediated p53 activation determines cellular outcome by regulating the expression of diverse genes that control cell cycle arrest and apoptosis. To explore the molecular mechanism of its functional diversities in apoptotic response, we first examined the expression levels of p53 proapoptotic targets, such as Bax, Noxa and Puma. Although the expression levels of Bax, Noxa and Puma proteins were significantly increased in Nbs1-deficient cerebella at P7 (as for positive control of apoptosis
A

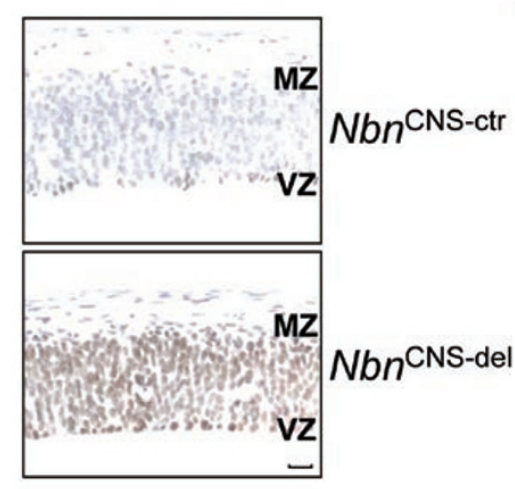

B

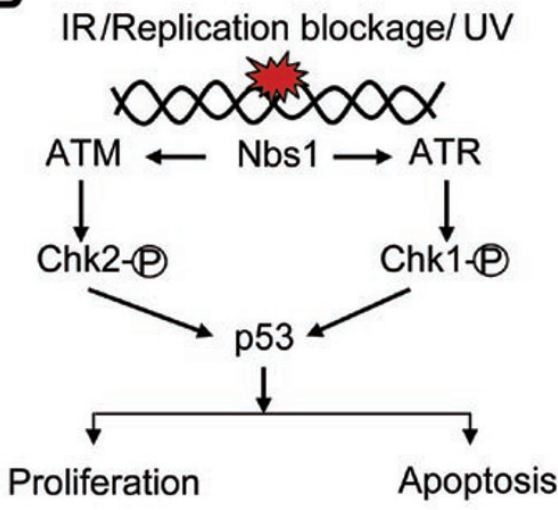

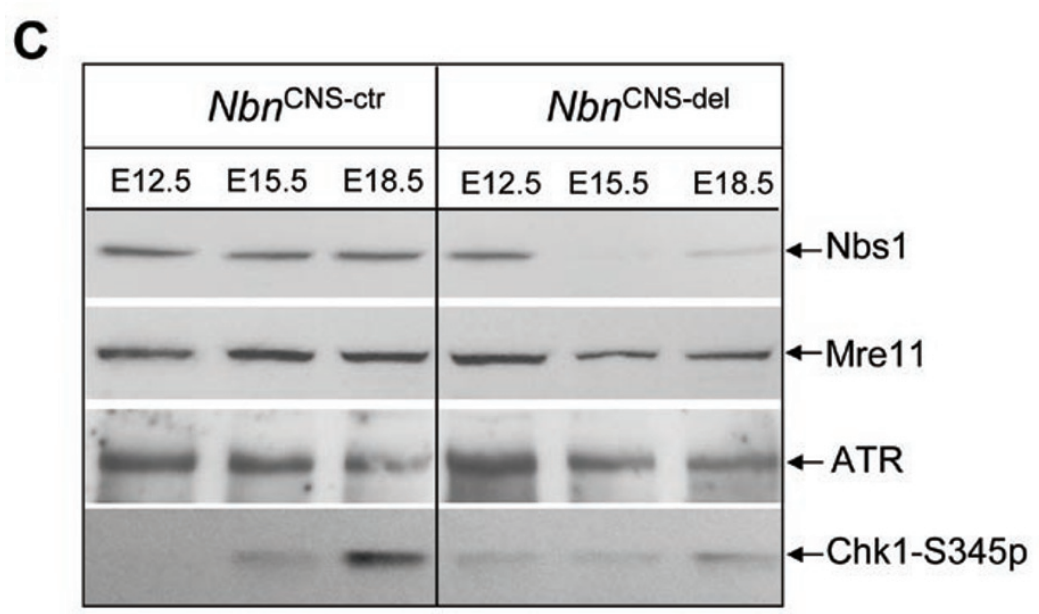

Figure 2 Nbs1 deficiency impairs ATR-Chk1 signaling in response to endogenous DNA damage in developing brain. (A) Accumulation of $\gamma \mathrm{H} 2 \mathrm{AX}$ exists in $\mathrm{VZ}$ and MZ of Nbs1-deficient embryonic brain at E12.5. Original magnification $\times 40$. (B) Schematic of the role of Nbs1 in response to DNA damage. (C) Nbs1 is required for the activation of ATR signaling during neurogenesis. Western blot analysis of the activation of ATR pathway in embryonic cortex. Note: In the absence of Nbs1, a marked reduction of Chk1-S345p at E15.5-18.5 during neurogenesis. 

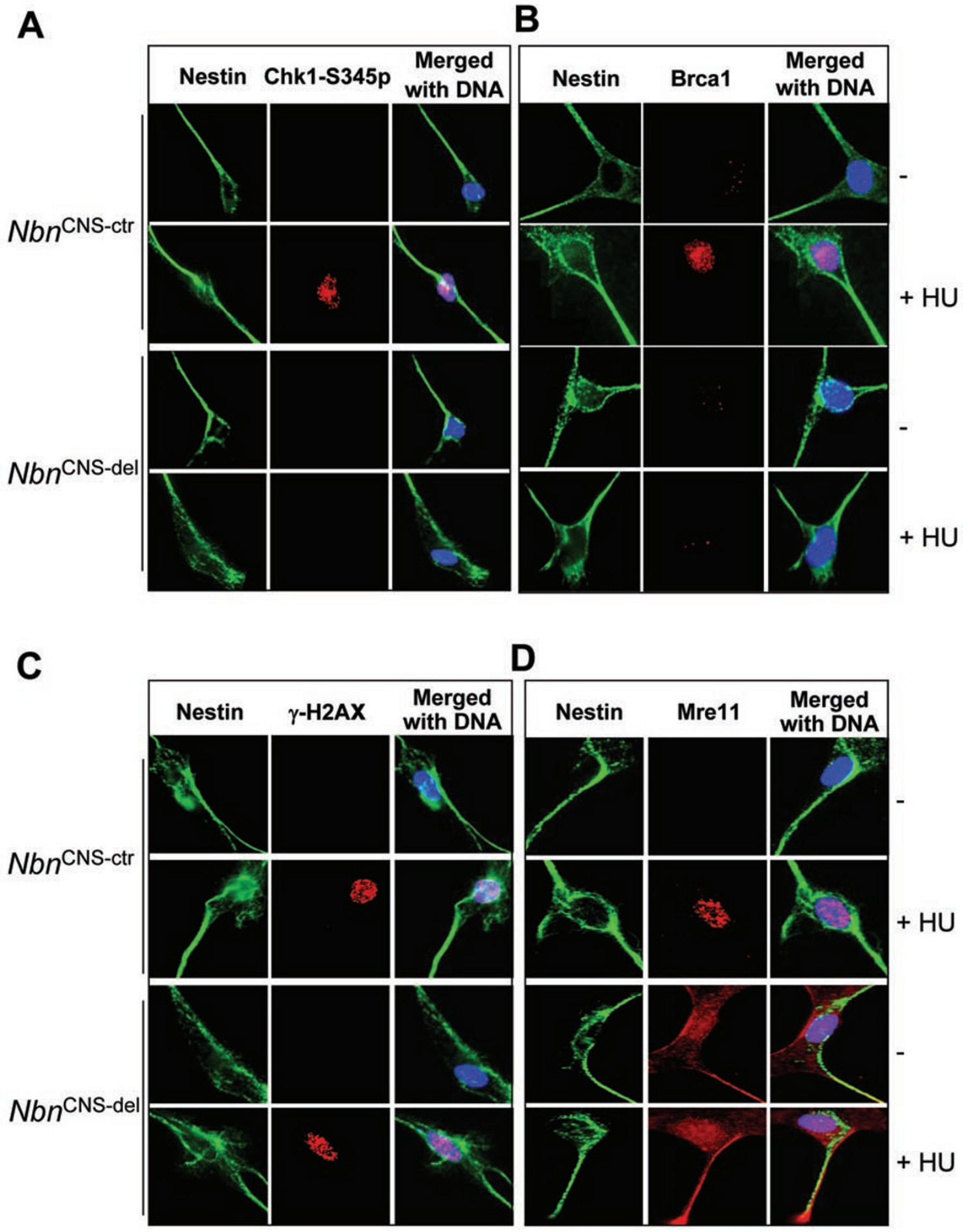

Figure 3 Nbs1 deficiency impairs phosphorylated Chk1 focus formation. Primary cultured $\mathrm{Nbn}^{\mathrm{CNS}-\mathrm{ctr}}$ and $\mathrm{Nbn}^{\mathrm{CNS}-\mathrm{del}}$ developing neurons were treated with $2 \mathrm{mM} \mathrm{HU}$ for $3 \mathrm{~h}$, and subjected to immunoflurescence staining with antibodies against phosphorylated Chk1-S345p (A), BRCA1 (B), $\gamma \mathrm{H} 2 \mathrm{AX}$ (C), and Nbs1 partner Mre11 (D). DAPI stains nuclei. The neuroprogenitors (A-D) are verified by nestin-positive immunoactivity, and at least 150 cells per staining were analyzed.

[18], Figure 5B), activation of p53 did not induce the expression of these proapoptotic proteins in neocortex of E13.5 embryos and cerebral cortex at P7 (Figure 5B). Notably, expression of antiapoptotic molecule Bcl-2 in 
A

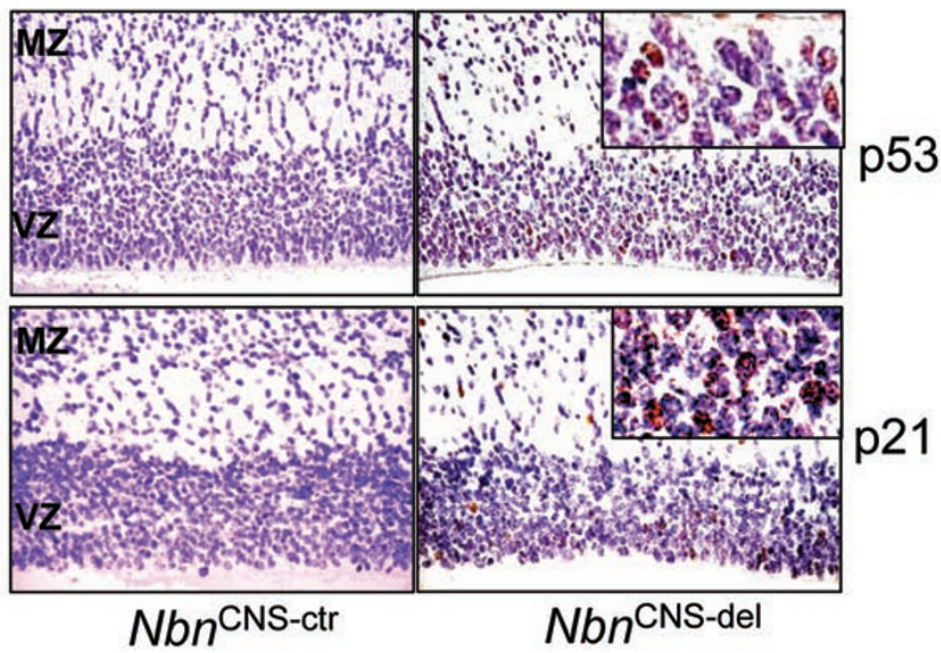

B

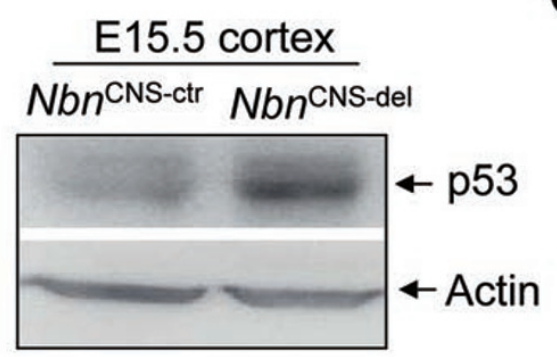

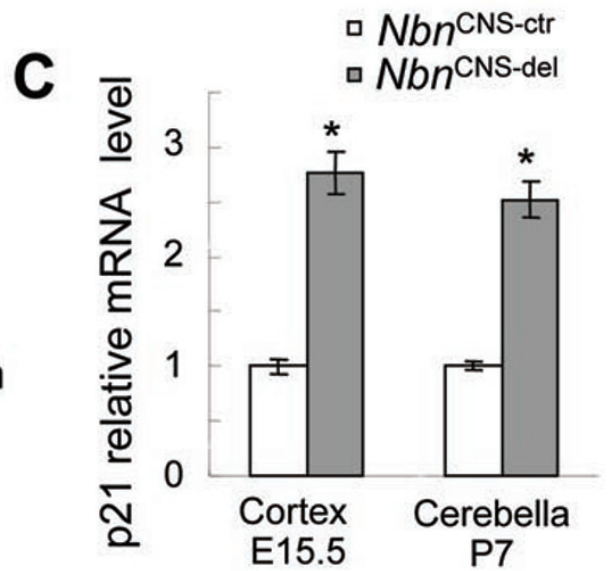

$\mathbf{E}$

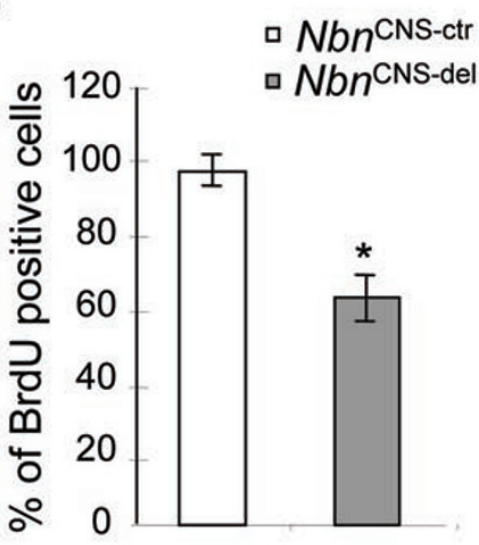

Figure 4 Nbs1 deficiency leads to defects in proliferation of neuroprogenitors during neurogenesis. (A) Activation of the p53 pathway in Nbs1-deficient embryonic cortex. Representative immunostaining of p53 and its downstream target p21 at E12.5. Original magnification $\times 40$. Insets: positive p53 and p21 cells. (B) Western blot analysis of the activation of p53 protein in E15.5 neocortex. (C) Nbs1 deficiency results in increased expression level of p53 target gene p21 in E15.5 neocortex and in P7 cerebella (as a positive control of inhibition of cell proliferation). (D) Representative in vivo BrdU labeling at E12.5. (E) Histogram representing percentage of BrdU-positive cells at VZ of 6 high-power fields from at least five mice of each genotype at $\mathrm{E} 12.5 .{ }^{*} P<0.01(t$ test). 
A

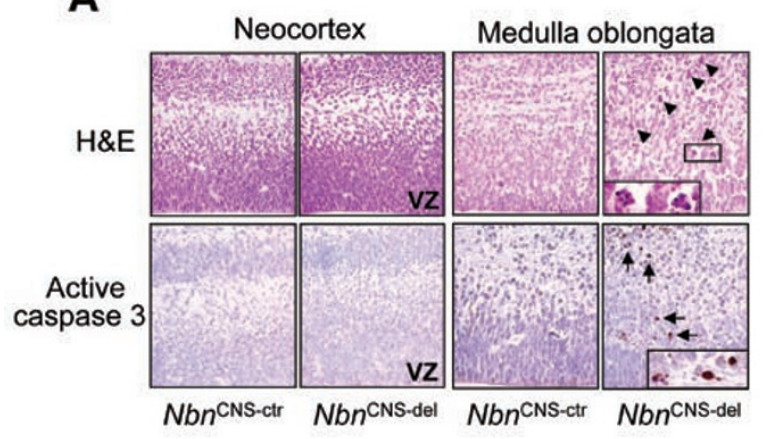

C

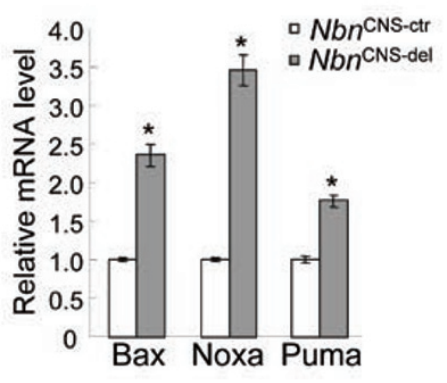

B

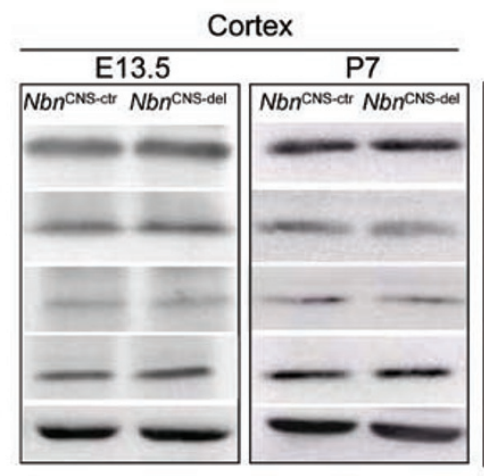

E

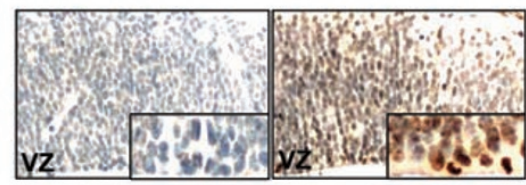

$\mathrm{Nbn} n^{\mathrm{CNS}-\mathrm{ctr}}$

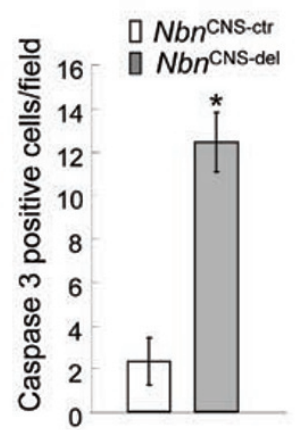

$\frac{\text { Cerebella }}{\text { P7 }}$

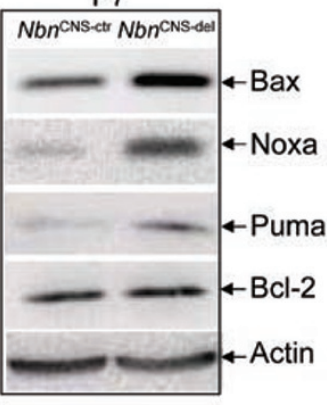

D

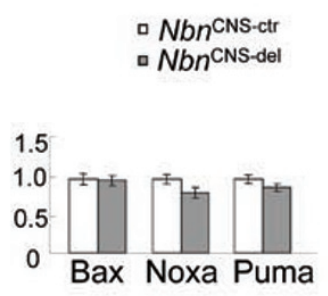

- NbnCNS-ctr

- NbnCNS-del

F

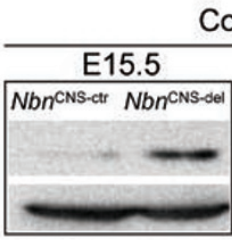

Cortex

\begin{tabular}{|c|}
\hline \multirow{2}{*}{$\frac{P 7}{N b n^{\text {CNS-ct }} N b n^{\text {CNS-del }}}$} \\
\hline \\
\hline$m-$ \\
\hline
\end{tabular}

\section{G}
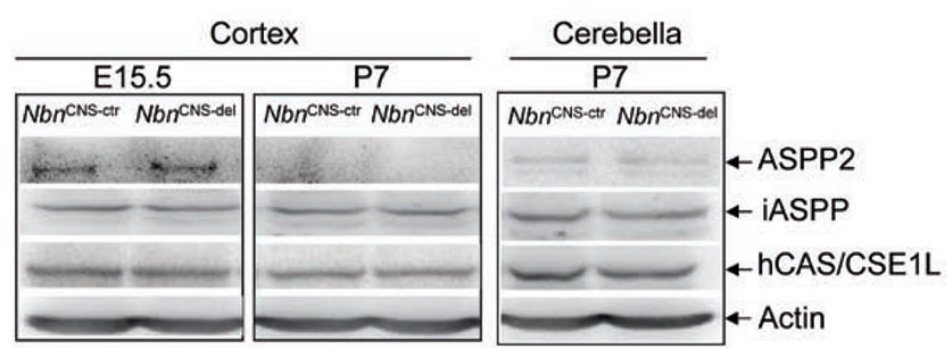

Figure 5 Role of Nbs1 in neuronal cell death. (A) H\&E and active caspase 3 immunostaining showing cell death in medulla oblongata at E12.5, but not in developing cortex at E15.5. Histogram representing percentage of active caspase 3-positive cells at medulla oblongata of six high-power fields from at least eight mice of each genotype at E12.5 (Original magnification $\times 40$ ). ${ }^{*} P<0.001$ ( $t$ test). (B) Nbs1 deficiency does not affect the expression of p53-dependent proapoptotic protein Bax, Noxa and Puma in neocortex at E13.5 and cerebral cortex at P7, but loss of Nbs1 alters cerebellar proapoptotic protein Bax, Noxa and Puma at P7. (C) Nbs1 deficiency results in increased expression levels of p53-mediated proapoptotic target genes Bax, Noxa and Puma in P7 cerebella, but has no effect on these gene expression in neocortex at E15.5 (D). At least six mice of each genotype were analyzed, ${ }^{*} P<0.05$ ( $t$ test). (E) Hzf immunoactivity in Nbs1-proficient and -deficient neocortex at E15.5 and E12.5 (inset). Original magnification $\times 40$. Insets: positive Hzf cells in VZ region. (F) Expression level of Hzf in E15.5, P7 Nbs1-proficient and -deficient cortex, and P7 cerebella. (G) Expression of ASPP2, iASPP and hCAS/CSE1L proteins in E15.5, P7 Nbs1-proficient and -deficient cortex, and P7 cerebella. 
Nbs1-deficient neocortex at E13.5 and cerebral cortex at P7 was comparable to that in Nbs1 control mice.

To further investigate the changes of p53-dependent proapoptotic proteins in $N b n^{C N S-d e l}$ brain were regulated at the transcriptional level, total RNAs from mouse neocortex and cerebella were subjected to quantitative real-time PCR analysis. Nbs1 deficiency significantly increased Bax, Noxa, and Puma mRNA levels in cerebella at P7 (Figure 5C), but had no obvious effect on these gene expression in neocortex at E15.5 (Figure 5D) and in cerebral cortex at P7 (Supplementary information, Figure S3).

Recent studies suggest that transactivation of p53dependent target genes can be modulated by different p53-interacting partners, thereby regulating cell cycle arrest and/or apoptosis [26]. It has been shown that hematopoietic zinc finger ( $\mathrm{Hzf}$ ), a zinc finger-containing p53 target gene, is induced by genotoxic and oxidative stress in a p53-dependent manner. Upon binding to p53, Hzf preferentially transactivates pro-arrest p53 target genes like $p 21$ over its proapoptotic target genes such as Bax, Noxa and Puma, resulting in growth arrest and apoptosis inhibition [27]. Thus, the ability of p53 to recruit to the promoters of cell cycle arrest target genes is directly regulated by Hzf. To investigate whether Hzf plays a role in Nbs1-deficient neuron, we first performed immunostaining for $\mathrm{Hzf}$ in Nbs1-deficient and -proficient neocortex at E12.5 and E15.5. Concomitant with p53 activation, the expression of Hzf was very high in the VZ of $N b n^{C N S-d e l}$ developing cortex but was nearly absent in $N b n^{\text {CNS-ctr }}$ neocortex at E12.5 (Figure 5E). Although Das et al. has demonstrated in vitro that following prolonged exposure to DNA damage or extended p53 expression/ activation leads to Hzf protein degradation, which in turn induces activation of proapoptotic p53 targets such as Bax, Puma and Noxa, resulting in apoptosis, we found that the induction of Hzf by p53 activation existed persistently in $\mathrm{Nbn}^{\mathrm{CNS}-\mathrm{del}}$ neocortex from E12.5 to E15.5, but not in medulla oblongata and primordial cerebellar neurons (Figure 5E and data not shown). Western blot analysis also showed that expression of Hzf was profoundly upregulated both in E15.5 and P7 Nbn ${ }^{\text {CNS-del }}$ cortex, but neuronal Nbs1 deficiency did not affect the expression of Hzf in cerebella at P7 (Figure 5F). This suggests that Hzf appears a different pattern of expression in response to endogenous DNA damage caused by Nbs1 deficiency during neurogenesis.

In addition to Hzf, we also analyzed other p53-interacting proteins in Nbs1-deficient neocortex. ASPP family members ASPP1 and ASPP2 interact with p53 and specifically enhance p53-induced apoptosis [28], while their inhibitor iASPP prevents p53 transcriptional activity from proapoptotic promoters by competing with ASPP1 and ASPP2 to bind p53 [29]. The human cellular apoptosis susceptibility protein hCAS/CSE1L associates with chromatin and regulates induction of selective p53 target genes and apoptosis [30]. In contrast to Hzf expression in $\mathrm{Nbn}^{\mathrm{CNS}-\mathrm{del}}$ cortex and cerebella, the expression of ASPP2, iASPP and hCAS/CSE1L remained unchanged compared to that in control mice (Figure 5G). Thus, Hzf likely plays a key role in sustaining p53-mediated cell cycle arrest and defective proliferation of neuroprogenitors in Nbs1-deficient neocortex.

Activation of p53 pathway is responsible for Nbs1-deficient microcephaly

DNA damage in different areas of $\mathrm{Nbn}^{\mathrm{CNS}-\mathrm{del}}$ brain induces activation of ATM target p53 protein (Figures 4A, $4 \mathrm{~B}$ and $6 \mathrm{~A}$ ), which controls genes expression, leading to developmental defects of brain [18]. To further evaluate the potential role of p53 in Nbs1-deficient microcephaly, we introduced Trp53 mutations in $N b n^{C N S-d e l}$ mice. Histopathological analysis of $N b n^{C N S-d e l} ; \operatorname{Tr} p 53^{+/+}$cerebra revealed microcephaly and all identical cerebral defects seen in $\mathrm{Nbn}{ }^{\mathrm{CNS}-\mathrm{del}}$ mice (data not shown). Trp53 heterozygosity had a marginal effect on the loss of brain weight and cerebral development defects in $\mathrm{Nbn}^{\mathrm{CNS}-\mathrm{del}}$ mice (Figure $6 \mathrm{~B}$ and $6 \mathrm{C}$; data not shown). Notably, null mutation of $\operatorname{Trp} 53$ significantly increased brain weight (Figure $6 \mathrm{~B})$, and substantially rescued the thickness of cortex $(\mathrm{Cx})$ and $\mathrm{CC}$ in $\mathrm{Nbn}^{\mathrm{CNS}-\mathrm{del}}$ mice (Figure $6 \mathrm{C}$ ). Moreover, null mutation of Trp53 largely increased granule cell numbers and improved the laminar structure in $N b n^{C N S-d e l} \mathrm{OB}$ (Supplementary information, Figure S1C).

To further understand the role of p53 on Hzf expression in Nbs1-deficient brain, we next investigated the expression level of Hzf in $\mathrm{Nbn} / \mathrm{Tr} p 53$ double mutant cortex and cerebella. Consistent with Nbs1-deficient neocortex,

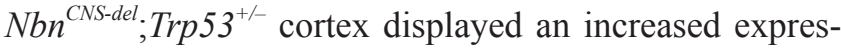
sion level of Hzf (Figure 6D), and Trp53 null mutation markedly reduced Hzf expression in $\mathrm{Nbn}^{\mathrm{CNS}-\mathrm{del}}$ cortex. Interestingly, Trp53 null mutation did not affect the expression of Hzf protein in $\mathrm{Nbn}^{\mathrm{CNS}-\mathrm{del}}$ cerebella (Figure 6D), implying that during neurogenesis p53-induced Hzf expression in $N b n^{C N S-d e l}$ brain is indeed in a region-specific manner.

\section{Discussion}

In the present study, we have shown that neural inactivation of Nbs1 leads to microcephaly in mice characterized by reduced size of cerebral cortex and thickness of $\mathrm{CC}$, resembling neuronal abnormalities of human NBS patients [31]. 
A

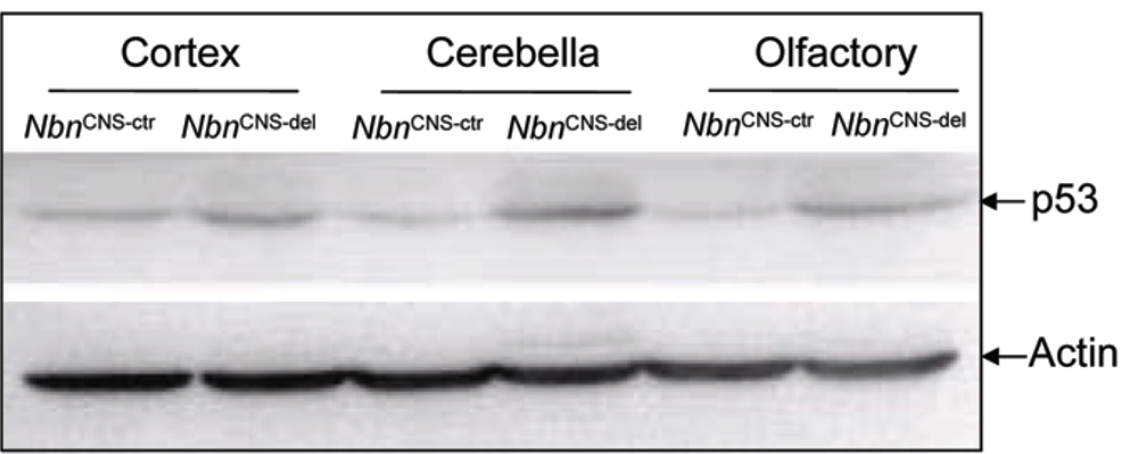

B

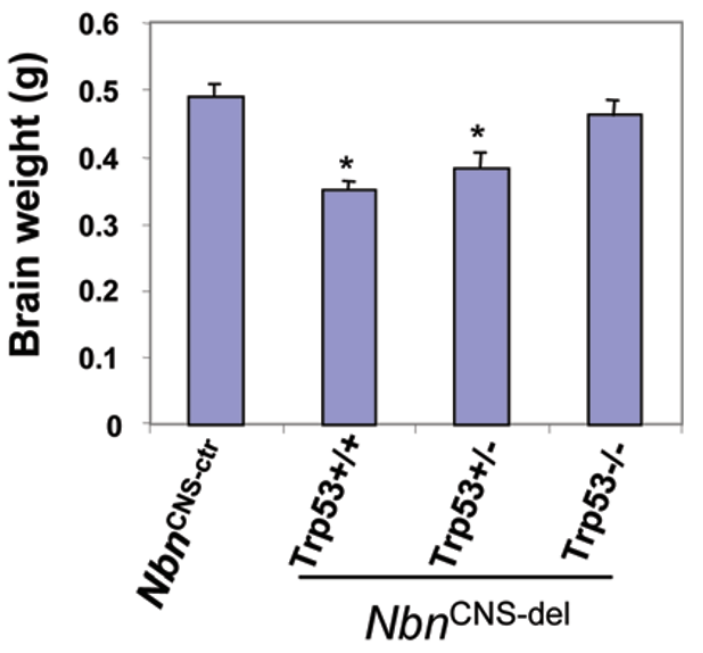

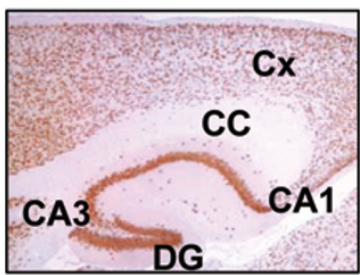

Nbn ${ }^{\mathrm{CNS}-\mathrm{ctr}}$

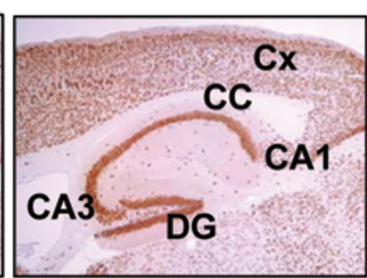

Trp53+/+

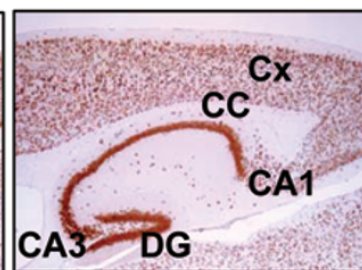

$\operatorname{Trp53+/-~}$

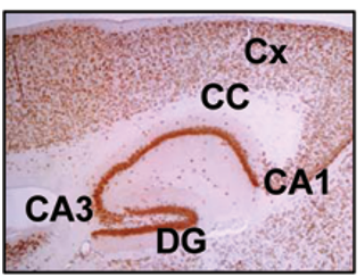

Trp53-/-

Nbn $n^{\text {CNS-del }}$

D

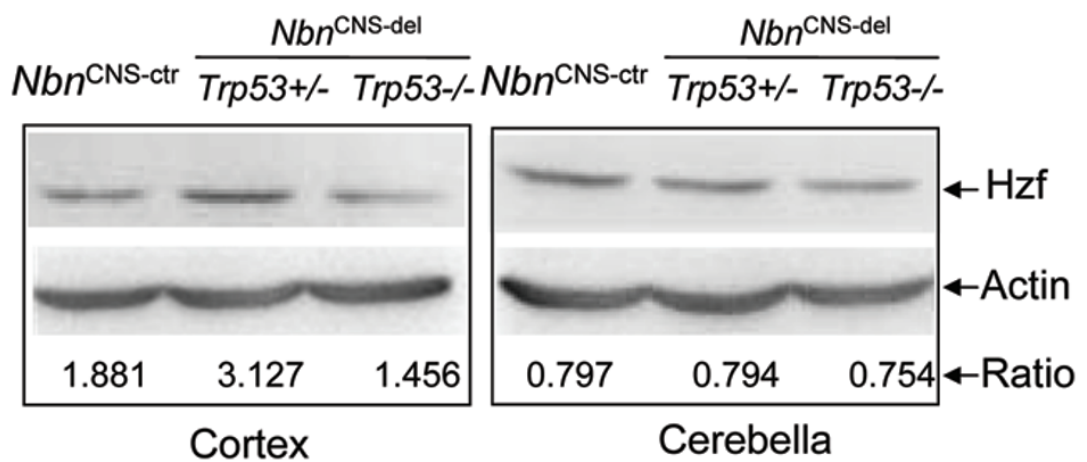

Figure 6 Introduction of Trp53 mutations in Nbs1-deficient brain largely rescues microcephaly. (A) Western blot analysis of p53 protein in Nbs1-deficient and -proficient brains at P7. (B) Brain weight from at least 10 mice of each genotype. ${ }^{*} P<0.01$ ( $t$ test). (C) Histological analysis of Trp53 mutant Nbs1-deficient cerebrum. Cx, cerebral cortex; CC, corpus callosum; DG, dentate gyrus; CA1/CA3, field CA1/CA3 of hippocampus. Original magnification $\times 4$. (D) Expression level of Hzf protein in P7 Trp53 mutant Nbs1-deficient cortex and cerebella. 
Development of the cerebral cortex is a strictly regulated process whereby neural progenitor cells from the proliferative pseudostratified ventricular zone go through massive expansion before they exit the cell cycle and form cortical neurons [32]. Neuroprogenitors are rapidly proliferating and potentially generate high level of oxidative damage, which may lead to a high level of lesions encountered at the replication fork [33]. Several pathways may execute to recognize and repair these lesions, unrepaired DNA strand breaks can cause detrimental outcome, including chromosomal instability, cell death, developmental defects and neoplastic transformation [34]. In particular, the nervous system is susceptible to DNA repair deficiency, which can lead to neurodegen-

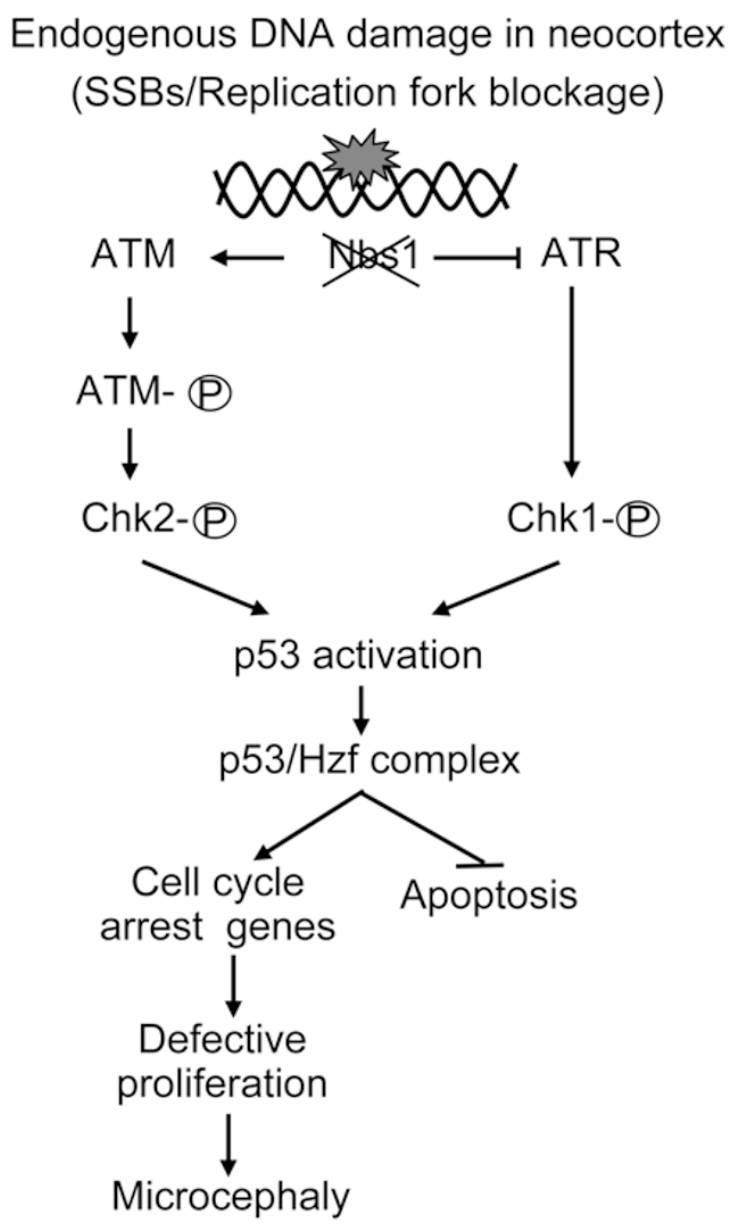

Figure 7 Working model for Nbs1 function and regulation in neocortex. Endogenous DNA damage during rapid development of neocortical neurons activates ATM-Chk2 and ATR-Chk1 signaling. However, defective Nbs1 impairs ATR-Chk1 pathway rather than ATM-Chk2 signaling. ATM-Chk2 signaling in Nbs1deficient neocortex activates p53-Hzf pathway and induces defective proliferation rather than apoptosis of neuroprogenitors, leading to microcephaly. eration, microcephaly or brain tumors [33]. Our study using developmental brain provides direct evidence that endogenous DNA damage caused by SSBs/replication fork blockage or DSBs activates ATR-Chk1 and ATMChk2-p53 pathways. Thus, it is likely that both ATM and ATR pathways participate in monitoring endogenous DNA damage during neurogenesis (see Figure 7).

It has been shown that $\mathrm{Nbs} 1$ is required to modulate ATM or ATR activation in vitro and in vivo $[3,8,11,25$, 35]. Notably, we show in the present study that Nbs1 dysfunction impairs the ATR-Chk1 signaling (see Figures 2 and 3), rather than the ATM-Chk2 pathway (see Supplementary information, Figure S2). It is likely that during neurogenesis, endogenous DNA damage caused by Nbs1 deficiency mainly leads to SSBs, such as replication fork blockage that activate ATR pathway. Although MRN complex activate ATM kinase [3], deletion of Nbs1 retained accumulation of Mre11 at cytoplasmic compartment, presumably inactivating the MRN function [36] (see Figure 3D). However, it has been shown recently that in neuroprogenior cells, ATM activation responding to DNA damage may not require Nbs1 [37]. Thus, defects in ATR-Chk1 signaling in Nbs1-deficient neocortical neurons may convert unrepaired replication fork to DSBs and result in a progressive accumulation of persistent DSBs throughout the brain, which in turn activate cell cycle checkpoint mediated by ATM-p53 pathway, leading to proliferation defects and microcephaly [38] (see Figure 7). In supporting this hypothesis, inactivation of Trp 53 largely rescues microcephaly in $\mathrm{Nbn}^{\mathrm{CNS}-}$ ${ }^{d e l}$ brain.

We have shown previously that Nbs1-deficient cerebellar neuroprogenitors are susceptible to DNA damage and postmitotic neurons with accumulation of DNA damage and chromosomal aberrations are cleared by massive cell death through activation of ATM-p53 signaling that leads to agenesis of cerebellum [18]. In the present study, although Nbs1-deficient cortical neuroprogenitors are susceptible to endogenous DNA damage that slows down proliferation (see Figure 4), distinct from cerebellar and medulla oblongata neurons, neocortical postmitotic neurons are more tolerable to DNA damage-induced cell death (see Figure 5A). Thus, the cerebrum continues to develop into microcephaly, which is likely due to proliferation defects. This functional difference of neurons in a specific region to endogenous DNA damage may be caused by a specific overactivation of Hzf upon ATMp53 signaling in neocortex (see Figure 5), which favors cell cycle arrest over apoptosis by selectively recruiting p53 to promoters of pro-arrest target gene such as $p 21$, resulting in proliferation arrest [27]. In contrast, in Nbs1deficient cerebella endogenous DNA damage enhanced 
p53-mediated cell death and proliferation arrest. Therefore, Hzf acts both as a p53 target (Figure 6) and as an important regulator in p53-mediated cell fate determination during cortical neurogenesis (see Figure 7). Thus, this study may partly explain the respective neuropathology in human that neurons at different regions of brain respond differently to endogenous DNA damage during neurogenesis.

In conclusion, the present study shows a role of $\mathrm{Nbs} 1$ in neocortical neurons by regulating ATR-Chk1 pathway in monitoring endogenous DNA damage. Neuronal Nbs1 deletion causes defective proliferation by activation of p53-Hzf signaling in neocortex, but not p53-mediated proapototic pathway, leading to microcephaly, and neurons display a region-specific response to endogenous DNA damage during neurogenesis. Thus, Nbs1-deficient mice present a useful model for further dissection of the molecular mechanisms of human NBS.

\section{Materials and Methods}

\section{Mice}

The generation and genotyping of $\mathrm{Nbs}^{\mathrm{F} 6 \mathrm{Fb}} ;$,nestin-Cre ${ }^{+}$(referred to as $N b n^{\text {CNS-del }}$ ) and Trp53-deficient $N b n^{\text {CNS-del }}$ mice has been described previously [18]. All animal experiments were approved by and performed in accordance with the guidelines of the International Agency for Research on Cancer's Animal Care and Use Committee and IBMS/PUMC's Animal Care and Use Committee.

\section{Histopathological analysis}

Animals were euthanized by carbon dioxide at the indicated time points. Whole mouse brains were fixed in $4 \%$ paraformaldehyde, followed by dehydration and paraffin embedding. Histopathological analysis was carried out on $3-\mu \mathrm{m}$-thick sections stained with hematoxylin and eosin (H\&E). Immunohistochemical staining was performed as described previously [39]. Antibodies included those specific for: mouse anti-NeuN (Millipore, Chemicon, Temecula, USA), rabbit anti- $\gamma \mathrm{H} 2 \mathrm{AX}$ (Abcam, Cambridge, UK), mouse anti-5-bromo-2'-deoxyuridine (BrdU, Sigma, Steinheim, Germany), rabbit anti-p53 (NovoCastra, Newcastle, UK), mouse anti-p21 (BD Pharmingen, San Jose, USA), and rabbit anti-active caspase 3 (Cell Signaling Technology, Danvers, USA), mouse anti-Hzf (Abnova, TaiPei, Taiwan). For the in vivo proliferation assay, we injected pregnant females intraperitoneally with $50 \mu \mathrm{g} \mathrm{BrdU/g}$ body weight. Embryos were collected $6 \mathrm{~h}$ after injection and fixed in $4 \%$ paraformaldehyde.

Quantifications of BrdU and active caspase-positive cells were performed from at least 5 to 10 embryos of each genotype, six high power fields $(\times 40)$ of each, and the thickness of $C C$ was measured at a point between CA1 and CA3 using a Zeiss Axioskop fluorescence microscope.

\section{Immunoblotting}

Proteins extracted from tissue and cells in RIPA buffer $(20 \mathrm{mM}$ HEPES pH 7.6, 20\% glycerol, $0.5 \mathrm{M} \mathrm{NaCl}, 1.5 \mathrm{mM} \mathrm{MgCl}_{2}, 0.2$ mM EDTA pH 8.0, 0.5\% NP-40, 1 mM DTT, 1 mM PMSF, $5 \mu \mathrm{g} /$ $\mathrm{ml}$ leupeptin, $2 \mu \mathrm{g} / \mathrm{ml}$ aprotinin, $1 \mathrm{mM} \beta$-glycerolphosphate, $1 \mathrm{mM}$ $\mathrm{Na}_{3} \mathrm{VO}_{4}$ and $10 \mathrm{mM} \mathrm{NaF}$ ) were resolved by SDS-PAGE, blotted and stained with antibodies in TBST containing $5 \%$ non-fat dried milk, followed by incubation with horseradish peroxidaseconjugated secondary antibodies and detected by the ECL reagents (Amersham Biosciences). The following antibodies were used: rabbit anti-Nbs1 (Oncogene, Swampscott, USA), mouse anti-ATM (Novus, Littleton, USA), mouse anti-ATM-S1987p (Rockland, Gilbertsville, USA), mouse anti-Chk2 (Millipore, Upstate, Temecula, USA), mouse anti-PARP-1 (R\&D systems, Minneapolis, USA), rabbit anti-ATR (Novus), rabbit anti-Chk1-S345p (Cell Signaling Technology), rabbit anti-Puma (Abcam), rabbit anti-Noxa (Abcam), rabbit anti-Bax (Millipore, Upstate, Temecula, USA), rabbit anti-Bcl-2 (Millipore, Upstate, Temecula, USA), mouse anti-p53 (Cell Signaling Technology, Danvers, USA), rabbit antiHzf (Santa Cruz Biotechnology, Santa Cruz, USA), mouse antiASPP2 (Sigma, St Louis, USA), mouse anti-iASPP (Sigma), rabbit anti-hCAS/CSE1L (Abcam) and mouse anti- $\beta$-actin (Santa Cruz Biotechnology).

\section{Focus formation and cell imaging}

Primary neurons from embryonic cortex at E13.5 were cultured as described previously [18]. To induce focus formation, cells were plated onto poly-D-lysine-coated coverslips, treated with or without $2 \mathrm{mM} \mathrm{HU}$ for $3 \mathrm{~h}$, and fixed. Immunofluorescence staining was performed as described previously [40]. Briefly, cells were washed once in PBS with $1 \mathrm{mM}$ glycerolphosphate, $1 \mathrm{mM} \mathrm{Na}_{3} \mathrm{VO}_{4}, 10$ $\mathrm{mM} \mathrm{NaF}$ and $1 \mathrm{mM}$ PMSF, and further treated with a hypotonic lysis solution containing $10 \mathrm{mM}$ Tris- $\mathrm{HCl} \mathrm{pH}$ 7.4, $2.5 \mathrm{mM} \mathrm{MgCl}$, $1 \mathrm{mM}$ PMSF, $1 \mathrm{mM}$ glycerolphosphate, $1 \mathrm{mM} \mathrm{Na}_{3} \mathrm{VO}_{4}, 10 \mathrm{mM}$ $\mathrm{NaF}$ and $0.5 \%$ Nonidet P-40 for 8 min on ice. Subsequently cells were fixed in ice-cold acetone-methanol (1:1) for $30 \mathrm{~min}$ on ice. The slides were then incubated with appropriate primary antibody in TBST containing 5\% non-fat dried milk. Slides were mounted in Vectashield mounting medium with DAPI (Vector Laboratories) and visualized under a Zeiss Axioskop fluorescence microscope equipped with a CCD imaging system (IP Lab Spectrum). A cell with at least five distinct foci in the nucleus was scored as focus positive, and at least 150 cells per staining were analyzed. Antibodies were specific for: mouse anti-nestin (Millipore, Chemicon, Temecula, USA), rabbit anti-phosphorylated $\mathrm{H} 2 \mathrm{AX}(\gamma \mathrm{H} 2 \mathrm{AX}$, Millipore, Upstate, Temecula, USA), rabbit anti-Mre11 (Novus), rabbit anti-Chk1-S345p (Cell Signaling Technology) and rabbit antiBRCA1 [41].

\section{Quantitative real-time $P C R$}

Total RNA was extracted from E15.5 mouse neocortex, P7 cerebella and cerebral cortex in TRIzol (Invitrogen), followed by chloroform extraction. First-strand cDNA synthesis from total RNA template $(2 \mu \mathrm{g})$ was performed with ReverTra Ace qPCR RT Kit (TOYOBO), oligo dT and random primers. The cDNA was amplified with a Bio-Rad iQ ${ }^{\mathrm{TM}} 5$ Multicolor Real-Time PCR Detection System, using SYBR Green Realtime PCR Master Mix (TOYOBO) and PAGE-purified primers (invitrogen). Primer sequences were as follows: $p 21$ (forward: 5'-ACATCTCAGGGCCGAAAAC-3'; reverse: 5'-CCTGACCCACAGCAGAAGA-3'), Puma (forward: 5'-CGTGTGGAGGAGGAGGAGT-3'; reverse: 5'-GGGAGGAGTCCCATGAAGA-3'), Noxa (forward: 5'-TGGAGTGCACCGGACATAAC-3'; reverse: 5'-AGCACACTCGTC- 
CTTCAAGTCT-3'), Bax (forward: 5'-GCAGAGGATGATTGCTGACG-3'; reverse, 5'- GGGCCTTGAGCACCAGTTT-3'), and $\beta$-actin (forward: 5'-TGTTACCAACTGGGACGACA-3'; reverse: 5'- GGGGTGTTGAAGGTCTCAAA-3').

\section{Statistical analysis}

All data were presented as mean values and standard error of mean (SEM). Differences between groups were compared by analysis of variance followed by $t$ test using Sigma plot software. $P$ value $<0.05$ was considered to be statistically significant.

\section{Acknowledgments}

This work was initiated in the International Agency for Research on Cancer (IARC), Lyon, France. We thank D Galendo (IARC) for the maintenance of the animal colonies, PO Frappart, N Lyndrate, C Carreira (IARC), L Lin and SY Hu (IBMS/PUMC) for technical support. We are also grateful to Dr E van Dyke (IARC) for helpful discussions and Dr CX Deng (NIH, USA) for BRCA1 antibody. This work was supported in part by La Ligue Nationale contre le Cancer, France, IBMS/PUMC Director's Fund (2007RC03), the National Natural Science Foundation of China (30970602), the National Novel Drug Development Fund (2009ZX09303-008) and 111 Project (B08007). ZQW is supported by Association for International Cancer Research (AICR), UK and the Deutschen Forschungsgemeinschaft (DFG), Germany. YGY is supported by the Hundred Talents Program of the Chinese Academy of Sciences.

\section{References}

1 Varon R, Vissinga C, Platzer M, et al. Nibrin, a novel DNA double-strand break repair protein, is mutated in Nijmegen breakage syndrome. Cell 1998; 93:467-476.

2 Riches LC, Lynch AM, Gooderham NJ. Early events in the mammalian response to DNA double-strand breaks. Mutagenesis 2008; 23:331-339.

3 Lee JH, Paull TT. ATM activation by DNA double-strand breaks through the Mre11-Rad50-Nbs1 complex. Science 2005; 308:551-554.

4 Difilippantonio S, Nussenzweig A. The NBS1-ATM connection revisited. Cell Cycle 2007; 6:2366-2370.

5 Jazayeri A, Balestrini A, Garner E, Haber JE, Costanzo V. Mre11-Rad50-Nbs1-dependent processing of DNA breaks generates oligonucleotides that stimulate ATM activity. EMBO J 2008; 27:1953-1962.

6 D' Amours D, Jackson SP. The Mre11 complex: at the crossroads of DNA repair and checkpoint signaling. Nat Rev Mol Cell Biol 2002; 3:317-327.

7 Stracker TH, Petrini JH. The MRE11 complex: starting from the ends. Nat Rev Mol Cell Biol 2011; 12:90-103.

8 Stiff T, Reis C, Alderton GK, Woodbine L, O'Driscoll M, Jeggo PA. Nbs1 is required for ATR- dependent phosphorylation events. EMBO J 2005; 24:199-208.

9 Olson E, Nievera CJ, Lee AYL, Chen LC, Wu Xh. The Mre11-Rad50-Nbs1 complex acts both upstream and downstream of ataxia telangiectasia mutated and Rad3-related protein (ATR) to regulate the S-phase checkpoint following UV treatment. J Biol Chem 2007; 282:22939-22952.

10 Jazayeri A, Falck J, Lukas C, et al. ATM- and cell cycle-dependent regulation of ATR in response to DNA double-strand breaks. Nat Cell Biol 2006; 8:37-45.

11 Shiotani B, Zou L. Single-stranded DNA orchestrates an ATM-to-ATR switch at DNA breaks. Mol Cell 2009; 33:547558.

12 O’Driscoll M, Ruiz-Perez VL, Woods CG, Jeggo PA, Goodship JA. A splicing mutation affecting expression of ataxia-telangiectasia and Rad3-related protein (ATR) results in Seckel syndrome. Nat Genet 2003; 33:497-501.

13 Jackson AP, Eastwood H, Bell SM, et al. Identification of microcephalin, a protein implicated in determining the size of the human brain. Am J Hum Genet 2002; 71:136-142.

14 Brown EJ, Baltimore D. ATR disruption leads to chromosomal fragmentation and early embryonic lethality. Genes Dev 2000; 14:397-402.

15 Zhu J, Petersen S, Tessarollo L, Nussenzweig A. Targeted disruption of the Nijmegen breakage syndrome gene NBS1 leads to early embryonic lethality in mice. Curr Biol 2001; 11:105109.

16 Kang J, Bronson RT, Xu Y. Targeted disruption of NBS1 reveals its roles in mouse development and DNA repair. $E M B O$ $J$ 2002; 21:1447-1455.

17 Yang YG, Frappart PO, Frappart L, Wang ZQ, Tong WM. A novel function of DNA repair molecule Nbs1 in terminal differentiation of the lens fibre cells and cataractogenesis. $D N A$ Repair (Amst) 2006; 5:885-893.

18 Frappart PO, Tong WM, Demuth I, et al. An essential function for NBS1 in the prevention of ataxia and cerebellar defects. Nat Med 2005; 11:538-544.

19 Assaf Y, Galron R, Shapira I, et al. MRI evidence of white matter damage in a mouse model of Nijmegen breakage syndrome. Exp Neurol 2008; 209:181-191.

20 Baranes K, Raz-Prag D, Nitzan A, et al. Conditional inactivation of the NBS1 gene in the mouse central nervous system leads to neurodegeneration and disorganization of the visual system. Exp Neurol 2009; 218:24-32.

21 Galron R, Gruber R, Lifshitz V, et al. Astrocyte dysfunction associated with cerebellar attrition in a Nijmegen Breakage Syndrome animal model. J Mol Neurosci 2011; 45:202-211

22 Hatten ME. Central nervous system neuronal migration. Annu Rev Neurosci 1999; 22:511-539.

23 Lee Y, Mckinnon PJ. Responding to DNA double strand breaks in the nervous system. Neuroscience 2007; 145:13651374.

24 Tibbetts RS, Cortez D, Brumbaugh KM, et al. Functional interactions between BRCA1 and the checkpoint kinase ATR during genotoxic stress. Genes Dev 2000; 14:2989-3002.

25 Yang YG, Saidi A, Frappart PO, et al. Conditional deletion of Nbs1 in murine cells reveals its role in branching repair pathways of DNA double-strand breaks. EMBO J 2006; 25:55275538.

26 Braithwaite AW, Del Sal G, Lu X. Some p53-binding proteins that can function as arbiters of life and death. Cell Death Differ 2006; 13:984-993.

27 Das S, Raj L, Zhao B, et al. Hzf determines cell survival upon genotoxic stress by modulating p53 transactivation. Cell 2007; 130:624-637. 
28 Samuels-Lev Y, O'Connor DJ, Bergamaschi D, et al. ASPP proteins specifically stimulate the apoptotic function of $\mathrm{p} 53$. Mol Cell 2001; 8:781-794.

29 Bergamaschi D, Samuels Y, Sullivan A, et al. iASPP preferentially binds $\mathrm{p} 53$ proline-rich region and modulates apoptotic function of codon 72-polymorphic p53. Nat Genet 2006; 38:1133-1141.

30 Tanaka T, Ohkubo S, Tatsuno I, Prives C. hCAS/CSE1L associates with chromatin and regulates expression of select $\mathrm{p} 53$ target genes. Cell 2007; 130:638-650.

31 Chrzanowska KH, Nekiesinska-Figatowsaka M, Józwiak S. Corpus callosum hypoplasia and associated brain anomalies in Nijmegen breakage syndrome. J Med Genet 2002; 39:e25.

32 Dehay C, Kennedy H. Cell-cycle control and cortical development. Nat Rev Neurosci 2007; 8:438-450.

33 McKinnon PJ. DNA repair deficiency and neurological disease. Nat Rev Neurosci 2009; 10:100-112.

34 McKinnon PJ, Caldecott KW. DNA strand break repair and human genetic disease. Annu Rev Genomics Hum Genet 2007; 8:37-55.

35 Shull ERP, Lee Y, Nakane H, et al. Differential DNA damage signaling accounts for distinct neural apoptotic responses in ATLD and NBS. Genes Dev 2009; 23:171-180.

36 Desai-Mehta A, Cerosaletti KM, Concannon P. Distinct functional domains of nibrin mediate Mre11 binding, focus formation, and nuclear localization. Mol Cell Biol 2001; 21:21842191.

37 Dar I, Yosha G, Elfassy R, et al. Investigation of the func- tional link between ATM and NBS1 in the DNA damage response (DDR) in the mouse cerebellum. J Biol Chem 2011; 286:15361-15376.

38 O'Driscoll M, Jeggo PA. The role of the DNA damage response pathways in brain development and microcephaly: Insight from human disorders. DNA Repair (Amst) 2008; 7:1039-1050.

39 Tong WM, Ohgaki H, Huang H, Granier C, Kleihues P, Wang ZQ. Null mutation of DNA strand break-binding molecule poly(ADP-ribose)polymerase causes medulloblastomas in p53(-/-) mice. Am J Pathol 2003; 162:343-352.

40 Yang YG, Herceg Z, Nakanishi K, et al. The Fanconi anemia group A protein modulates homologous repair of DNA double-strand breaks in mammalian cells. Carcinogenesis 2005; 26:1731-1740.

41 Turner JM, Aprelikova O, Xu X, et al. BRCA1, histone $\mathrm{H} 2 \mathrm{AX}$ phosphorylation, and male meiotic sex chromosome inactivation. Curr Biol 2004; 14:2135-2142.

(Supplementary information is linked to the online version of the paper on the Cell Research website.)

(a) This work is licensed under the Creative Commons Attribution-NonCommercial-No Derivative Works 3.0 Unported License. To view a copy of this license, visit http:// creativecommons.org/licenses/by-nc-nd/3.0 